\title{
Joining by Plating: Optimization of Occluded Angle
}

J. W. Dini, H. R. Johnson, Y. R. Kan

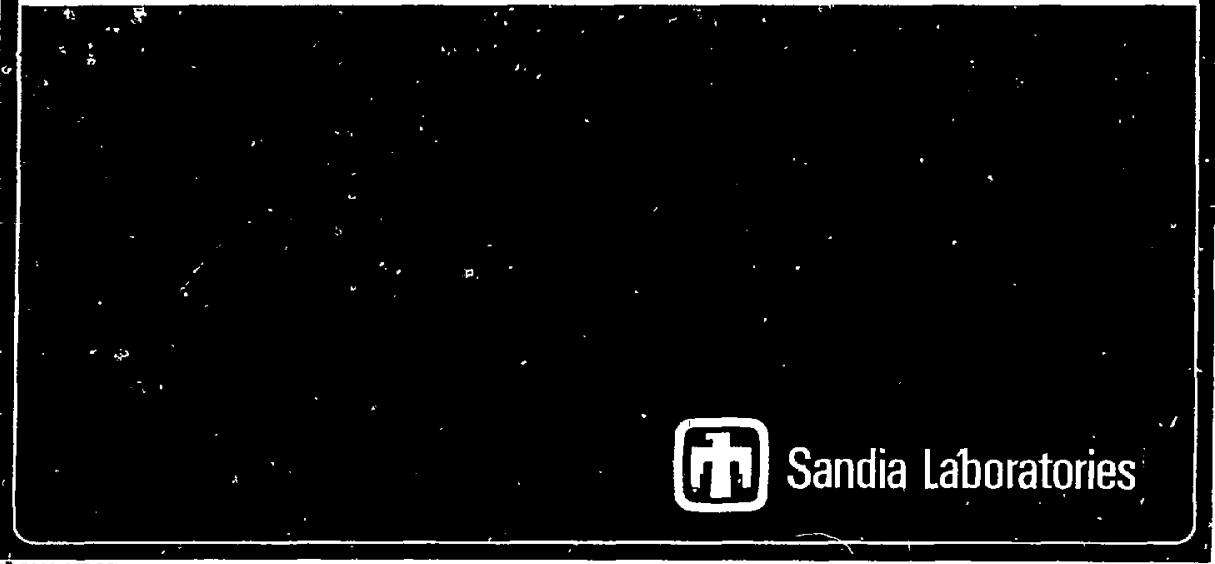

$\left.s^{*} 2900017.73\right)$

\section{MASTER}




\author{
SAND78-8027 \\ Unlimited Release \\ Printed November 1978
}

JONING BY PLATING: OPTIMIZATION OF OCCLUDED ANGLE

J. W. Dini and H. R. Johnson

Materials Development Division I, 8312

Y. R. Kan

Applied Mechanics Division 8122

Sandia Laboratories, Livermore

\begin{abstract}
An empirical nethod has been developed for predicting the minimum angle required for maximum joint strength for materials joined by plating. This is done through a proposed power law failure function, whose coefficients are taken from ring shear and conical head tensile data for plating/substrate combinations and whose exponent is determined from one set of plated-joint data. Experimental results are presented for Al-Ni-Al (7075-T6) and A M.363-Ni-A M363 joints, and the failure function is used to predict joint strengths for A1-Ni-Al (2024-T6), UTi-Ni-UTi, and Be-Ti-Be.
\end{abstract}




\section{CONTENTS}

Page

I. Introduction 9

II. Ring Shear and Tension Test Data for Nickel Plating

III. Phenomenological Joint-Strength Function

IV. Plated-Joint Data 20

V. Comparison of Theory 2.nd Experiment 25

VI. Conclusions 31

References 33 


\section{ILLUSTRATIONS}

Figure

Page

1. Steps in the Joining-by-Plating 10

2. Ring Shear Test Specimen 12

3. Conical Head Test Specimen 13

4. Typical Plated Joint With Occluded Angle $\alpha$ Under an 16 Axial Load $\sigma$

5. Plots of the Failure Function $f\left(\sigma_{n}, \tau\right)=0$ in the $\sigma_{n}-\tau$

6. Joint Strength $\sigma$ as a Function of Occluded Angle $\alpha$, Eq. (3), for Various Values of $\mathbf{N}$

7. Specifications for Tapered Joints 21

8. Examples of Rods Joined by Plating 22

9. Joint-Strength Date. (Circles) as a Function of Occluded Angle for Al-Ni-Ai (7075-T6)

10. Joint-Strength Data (Circles) as a Function of Occluded Angle for AM363-Ni-AM363

11. Fit of the Joint-Strength Function as a Function of

12. Comparison of the Joint-Strength Function for $\mathbf{N}=1.2$ (Solid Line) With Data for A M363-Ni-A M363

13. Predicted Joint-Strength as a Function of Occluded 
15. Predicted Joint Strength as a Function of Occluded Angle for Be-Ni-Be

\section{TABLIBS}

$\underline{\text { Table }}$

I. Bond Strengths for Various Materials Plated With Nickel

II. Pridicted and Measured Optimum Occluded Angles 
JOINING BY PLATING: OPTIMIZATION OF OCCLUDED ANGLE

\section{Introduction}

Electroplating is sometimes used to join metals that cannot be joined by conventional techniques. ${ }^{1,2}$ The process typically includes the machining of a taper on the parts to be joined, mating them, and building up the tapered region with thick electrodeposit, and ther machining to final dimensions. Figure 1 shows the joining process pistorially. Complete details on the technique including applications and property data have already been reported. 1, 2 The influence of the taper angle on the mechanical performance of the joint has not been rigorously addressed. Rather, design criterin, intuition, and experience have been nsed as guides to aid those wanting to use the process. The purpose of this work is to provide a method for analyzing the influence of the degree of taper on joint strength so that one can predict the minimum angle needed for optimum adhesion without having to fabricate and test a liarge number of joints.

In sectiori II we present the results of? shear and tension tests for nickel plating, the most commonly used electrodeposit for joining applications. The bond strengths obtained provide the primary input to the calculations. In section III a failure function for plated joints is proposed. It gives the joint 
strength as a function of occluded angle, and is in the form of a power law whose exponent $\mathrm{N}$ must (at least within the scope of the analysis in this paper) be determined from a fit to one set of plate-joint data. Nickel-plated-joint experiments are taken up in section IV. From the aluminum data a determiration of $\mathrm{N}$ is made and used to predict joint strengths for other parent materials (section V). A comparison of the theoretical calculations is made with A M363 stainless-steel joint data. Conclusions are given in section VI.

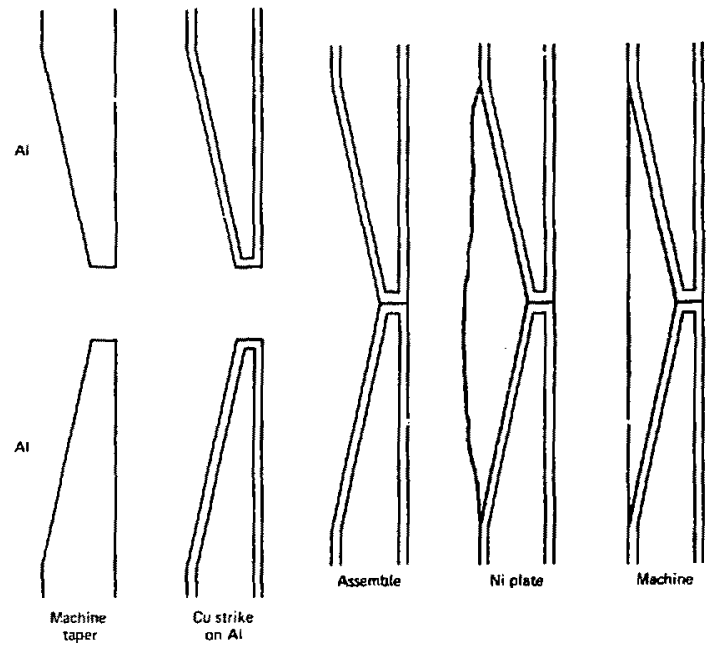

Figure 1. Steps in the Joining-by-Plating Process 


\section{Ring Shear and Tension Test Data for Nickel Plating}

Quantitative shear and tensile strengths of plating-substrate combinations are more easily obtained than plated joint strength data. The techniques for obtaining these bond-strength data are basically as follows:

For the ring shear test, a cylindrical rod is coated with separate rings of electrodeposit of predetermined width. The rod is forced through a hole in a hardened steel die, the hole diameter being greater than that of the rod but less than that of the rod ard the coating (Figure 2). The bond strength (interface shear strength) $S_{S}$ (in $\mathrm{MN} / \mathrm{m}^{2}$ or $\mathrm{psi}$ ) is determined by the formula $S_{S}=W / \pi d t$, where $d$ is the diameter of the rod, $t$ the width of the deposit, and $W$ the force required to cause failure in the specimen.

For the tension test, samples are prepared by plating a flat substrate on both sides with thick electrodeposit. Conical-head specimens are machined from the composite and then tested with standard tension testing procedures. Figure 3 shows specimen dimensions and a cut-away view of a specimen under test. The normal tensile strength $S_{n}$ is found from the formula $S_{n}=W /\left(\pi d^{2} / 4\right)$.

Details for both of these tests are included in Reference 3 along with data and references for substrate-coating combinations tested by these techniques. Table I includes ring shear and conical-head tenzile test data for a number of substrates of interest for potential joining by nickel plating applications. Included are values for 7075-T6 aluminum and AM363 stain?ess steel. 


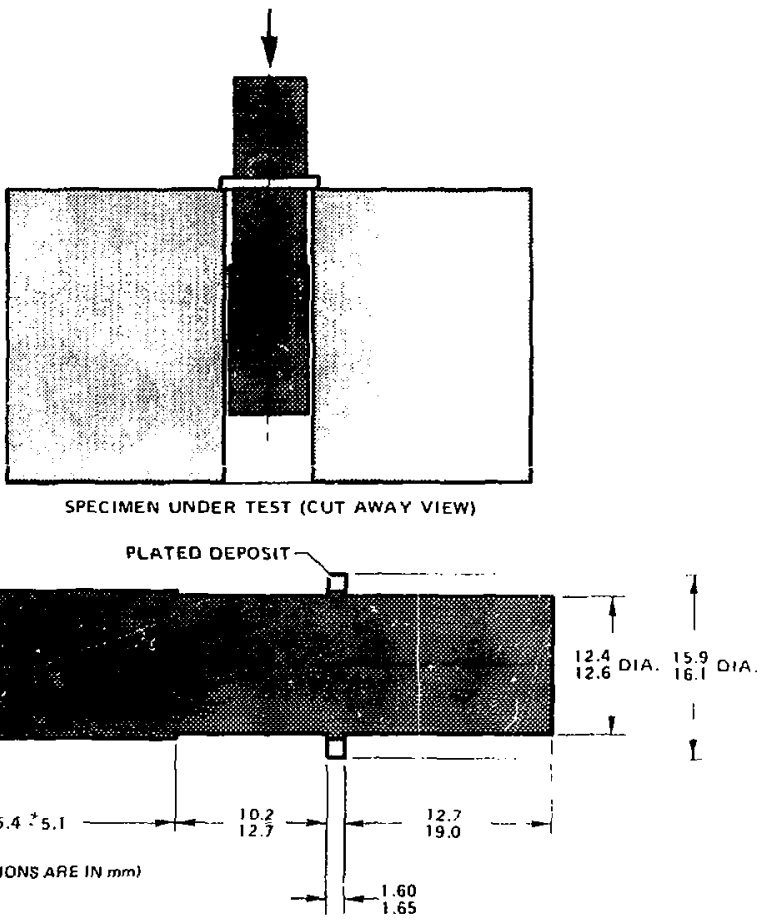

Figure 2. Ring Shear Test Specimen 


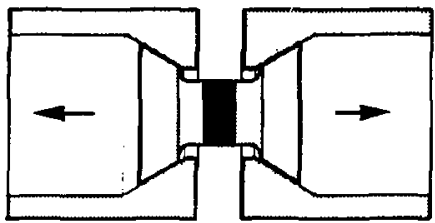

SPECIMEN UNDER TEST [CUT AWAY V!EW]

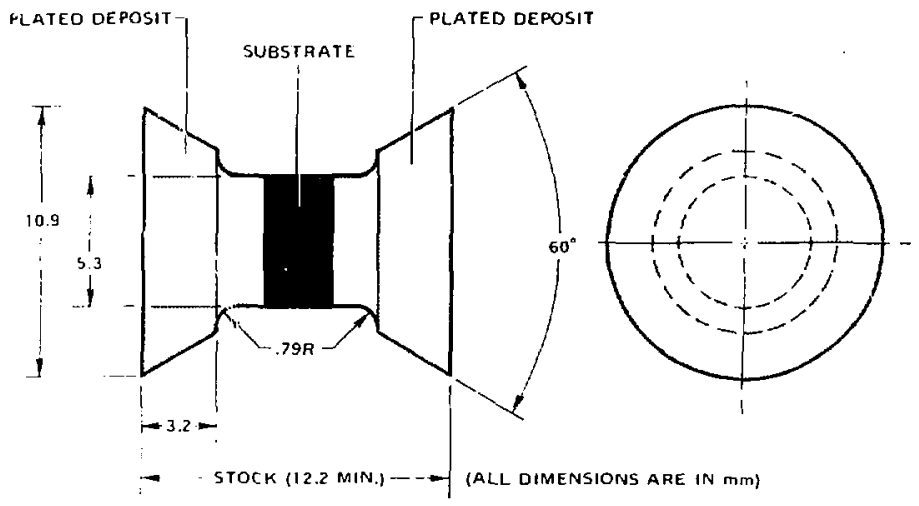

Figure 3. Conica! Head Test Specimen 
A comparison of the shear to tensile ratios for these two materials shows a wide variation, from 0.44 for aluminum compared to 0.94 for the AM363. These data were used to compute theoretical joint strengths as discussed in the following section.

TABLE I

BOND STRENGTHS FOR VARIOUS MATERIALS PLATED WITH NICKELA

\begin{tabular}{|c|c|c|c|c|c|}
\hline Material & $\begin{array}{l}\text { Conical } \\
\text { Tensile S } \\
\left(\mathrm{MN} / \mathrm{m}^{2 !}\right.\end{array}$ & $\begin{array}{l}\text { Head } \\
\text { rength } \\
\text { (pgi) }\end{array}$ & $\begin{array}{r}\text { Ring S1 } \\
\text { Stren } \\
\left(\mathrm{MN} / \mathrm{m}^{2}\right)\end{array}$ & $\begin{array}{l}\text { ear } \\
\frac{\text { th }}{(p i)}\end{array}$ & $\begin{array}{c}\text { Shear/Tensile } \\
\text { Ratio }\end{array}$ \\
\hline Beryllium & 317 & 46,000 & 252 & 36,500 & 0.79 \\
\hline $\begin{array}{c}\text { Uranium }-0.8 \\
\text { Titanium }\end{array}$ & 507 & 73,500 & 247 & 35,800 & 0.49 \\
\hline Aluminum (7075-T6) & 572 & 83,000 & 250 & 36,200 & 0.44 \\
\hline Aluminum (2024-T6) & 445 & 64,500 & 221 & 32,000 & 0.50 \\
\hline $\begin{array}{l}\text { Stainless Steel } \\
\text { (AM363) }\end{array}$ & 490 & 71,000 & 455 & 60,000 & 0.94 \\
\hline
\end{tabular}

${ }^{a}$ See reference 3 for details of these tests. Plating was done in a nickel sulfamate solution. 


\section{Phenomenological Joint-Strength Function}

The objective of this analysis is to determine the minimum occluded angle $\alpha$ for optimum joint strength using the interface shear strength $S_{\mathbf{S}}$ and tensile strength $S_{n}$ obtained experimentally from the ring shear and tension tests, respectively. However, as it will turn out, because of our lack of knowledge of how $S_{s}$ and $S_{n}$ interact to comprise the joint strength, it is also necessary to have some representative joint data for one parent material. The method of approach will be first to estahlish a failure criterion for the bonding interface. This will be used to find the joint strength as a function of $S_{S}, S_{n}, \alpha$, and a parameter $N$ which contains information on the coupling between $S_{s}$ and $S_{n}$. A fit of the failure function to one set of joint data will then determine the value of $\mathrm{N}$ for that plating material, and thus $\alpha_{\text {min }}$ can be predicted for other parent materials with the same plating material.

When a joint is loaded axially, the bonded interface is under combined shear and tensile stresses. Figure 4 shows a sketch of a typical plated joint, with an occluded angle $\alpha$, subjected to a nominal axial load $\sigma$ applied at both ends. The detailed elastic stress field in the joint is very complex, and is a strong function of $\alpha$ and the parent and plated material properties. At the failure load, however, the stress state at the bonding interface is uniform because of the plasticity effert. The tensile stress $\sigma_{n}$ and shear stress $\tau$ in the interface can be calculated from the equilibrium condition by the formulas 


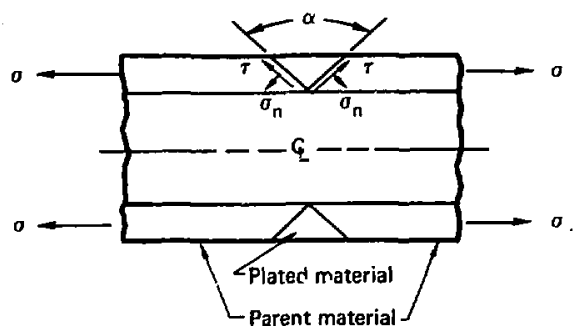

Figure 4. Typical Plated Joint With Occluded Angle $a$ Under an Axial Load $a$. $\tau$ and $\sigma_{n}$ are the tensile and shear stresses, respectively.

$$
\begin{aligned}
\sigma_{n} & =\frac{1}{2} \sigma(1+\cos \alpha), \\
\tau & =\frac{1}{2} \sigma \sin \alpha .
\end{aligned}
$$

The proposed interface failure function is based on ideas developed by Mises and by Tresca. ${ }^{4}$ The form sugsested by their work it

$$
f\left(s_{n}, \tau\right)=\left[\left(\sigma_{n} / S_{n}\right)^{N}+\left(\tau / S_{s}\right)^{N}\right]^{1 / N}-1
$$

where $S_{n}$ is the normal tensile stren-th obtiined from the conical head tension test, $S_{S}$ the shear strength obtained from the ring shear test, and $\mathrm{N}$ a dimensionless constant (which will need to be determined from joint strength data). The experimentallv determined $S_{n}=W /\left(\pi d^{2} / 4\right)$ and $S_{S}=W / \pi$ dt do not take stress concentration into account. However, this is justifiable since any stress concentration at the bonding interface must be smoothed by local plasticity at the failure load so that the shear and tengile stresses are in fact uniform. 
The failure function $f\left(\sigma_{n}, \tau\right)$ will never be greater than zero, and the failure criterion is $f\left(\sigma_{n}, \tau\right)=0$. For $N=2$ and $S_{S} / S_{n}=1 / \sqrt{3}, f\left(\sigma_{n}, \tau\right)$ becomes Mises' maximum distortion energy yield criterion for an isotropic material, while for $N=2$ and $S_{s} / S_{n}=1 / 2$ it is Tresca's maximum shear stress yield criterion. Both Mises' and Tresca's criteria incorporate the fact that the first stress invariant (the hydrostatic component) has no effect on yielding of the isotropic material. In plated joints, however, the ratio of shear to tensile

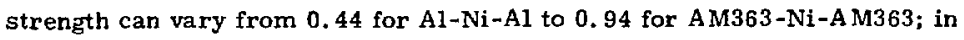
addition, the hydrostatic stress component does affect the failure at the interface. Therefore, even though the proposed failure function has the same form as Nises' and Tresca's yield criteria, it cannot be assumed that $\mathrm{N}=2$ will work. The value of $\mathrm{N}$ will depend on the degree of inteiaction between the shear and tensile stresses.

Figure 5 shows the failure function $f\left(\sigma_{n}, \tau\right)$ for some specific values of $N$. $N=\infty$ corresponds to no interaction between the shear and tensile stresses so that the presence of shear stress will not reduce the tensile strength of the interface, and vice versa. When $N=2$, the Mises or Tresca ellipse, there is mild interaction; when $N=1$, there is very strong interaction. Because of the interaction, the shear stress component considerably reduces the tensile strength of the interface.

By substituting $\sigma_{n}$ and $\tau$ of Eq. (1) into the failure function, the joint strength $\sigma$ can be expressed in terms of the occluded angle $\alpha$, interface tensile strength $S_{n}$, shear strength $S_{S}$, and $N$ by the equation 


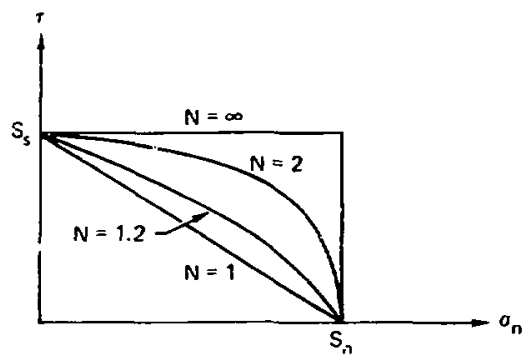

Figure 5. Plots of the Failure Function $f\left(\sigma_{n}, \tau\right)=0$ in the $\sigma_{n}-\tau$ Plane for Various Values of Exponent $N$

$$
\sigma=\left\{\left(\frac{\frac{1}{2}+\frac{1}{2} \cos \alpha}{s_{n}}\right)^{N}+\left(\frac{\frac{1}{2} \sin \alpha}{S_{s}}\right)^{N}\right\}^{-\frac{1}{N}} .
$$

The effect of power $\mathrm{N}$ on the joint strength $\sigma$ at various occluded anples is plotted in Figure 6 for given interface tensile and shear strengths. The joint strength has a value of $S_{n}$ at $\alpha=0$ for all values of $N$ when $S_{n}<S_{F}$, the strength of the parent material. For low $\mathrm{N}, \sigma$ first decreases with increasing $\alpha$, reflecting the interaction between the shear and tensile stress components. The horizontal line $\sigma=S_{p}$ at larger values of $\alpha$ represents the tensile strength of the weakest material. Since joints can never be stronger than the tensile strength of the parent material, for large occluded angles the joint will fail in the parent material instead of the interface if angle $\alpha$ for $\sigma=S_{p}$ is the minimum occluded angle required to achieve the maximum joint strength. The value of $\mathrm{N}$ for joints with a given plating is determined from a fit of $\sigma$, as given in Figure 6, to a representative set of joint strength data. 


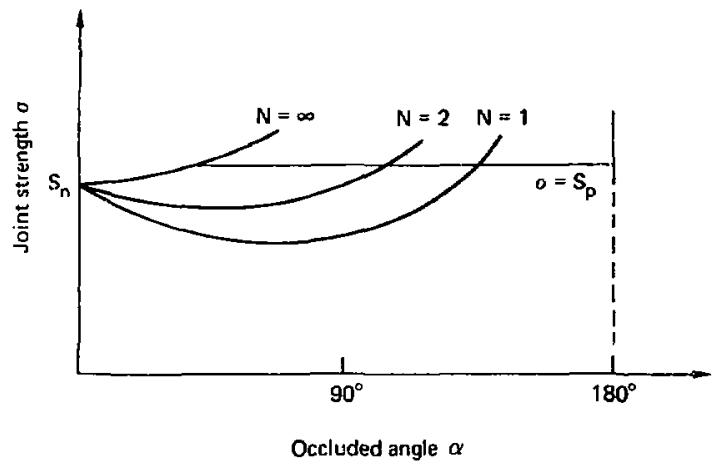

Figure 6. Joint Strength $\sigma$ as a Function of Occluded Angle a, Eq. (3), for Various Values of $N$. The horizontal line $\sigma=S_{p}$ represents the strength of the parent material 


\section{Plated-Joint D-ta}

Since: the widest variation in the ratio of shear to tensile strength in Table I is found for aluminum and stainless steel, it was decided to determine $\mathrm{N}$ from a fit to aluminum-nickel joint strength data and, based on that $\mathrm{N}$ value, to test the predicted values of joint strength against stainless steel data. One's confidence in the phenomenological theory for use with other parent materials would depend on the goodness of fit.

We joined alurninum rods (7075-T6) wich nickel plating. The same was done with AM363 stainless-steel rods. On both sets of rods, tapers ranging from 4 to 55 degrees were used (Figure 7). All rods had an inner diameter of $3.2 \mathrm{~mm}(0.125 \mathrm{in.})$ and a wall thickness of $1.59 \mathrm{~mm}(0.0625 \mathrm{in.})$. For the joining process, an aluminum cylineter slightly less than $3.2 \mathrm{~mm}(0.125 \mathrm{in}$.) in diameter was inserted through the I. D. of the specimens to provide support and keep them aligned during nickel plating.

The zinc imnersion method (zincating) was used for preparing aluminum for plating. This provides an adherent base onto which other metals can be deposited. For preparing stainless steel for plating, a Wood's nickel strike

was used. 5 With this method, the oxide film ir removed and replaced with a thin film of nickel, which serves as a base for subsequent plating.

After plating, the cylinders were removed and the outer diameters of the joined parts machined to final dimensions. Figure 8 shows some rods 


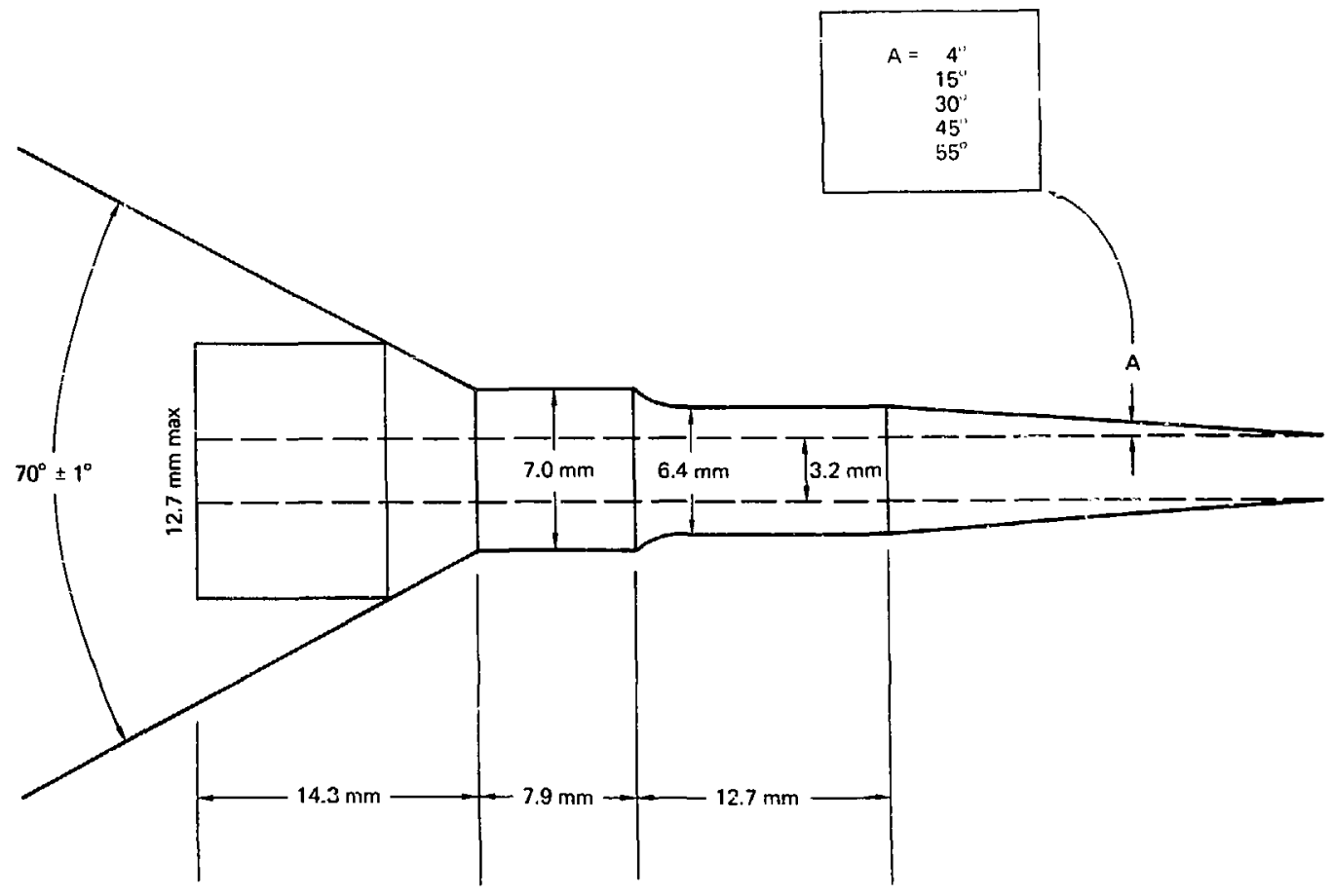




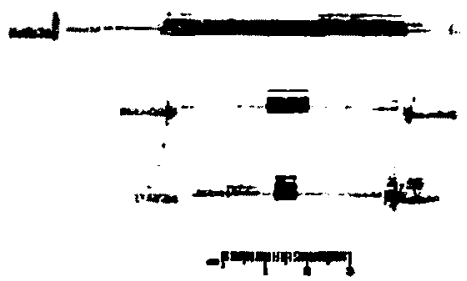

Figure B. Examples of Rots Joint:l hy Plating. Shown are tubs: specimens with a $4^{\circ}$ taper (top), $15^{\circ}$ taper (midule),

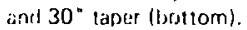

after joining. The rols were tisted to falur: by using an instron machine and specially designed jaws.

The data for aluminum rods joined by nickel plating arc presented in Figure 9. They show that maximum strength joints wore obtained whenever the occluded angle was 120 degrees or greater. For angles less than 120 degrees, joint strengths progressively decreased as the occluded angle decreased. For occluded angles of 120 degrees or greater, failure always occurred in the aluminum. When the occluded angle was less than 120 degrees, failure occurred at the interface between the aluminum and the plating.

Ine iata for the AM363 stainless-steel rods joined by nickel plating are presented in Figure 10. Maximum strength joints were obtained when the occluded angle was 90 degrees or greater. 


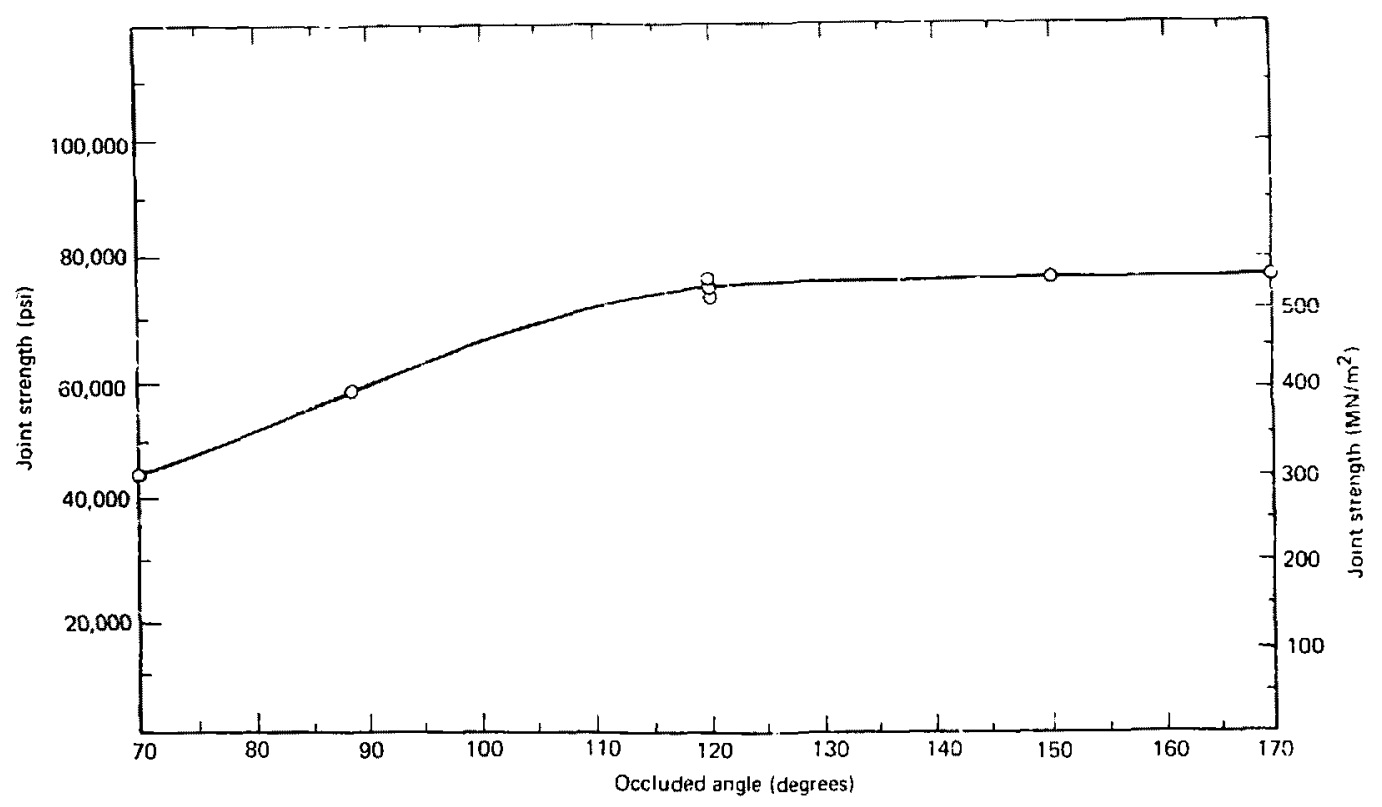

Figure 9. Joint.Strength Data (Circles) as a Function of Dccluded Angle for Al-Ni-Al (7075.T6).

The curve is a guide for the eye only. 


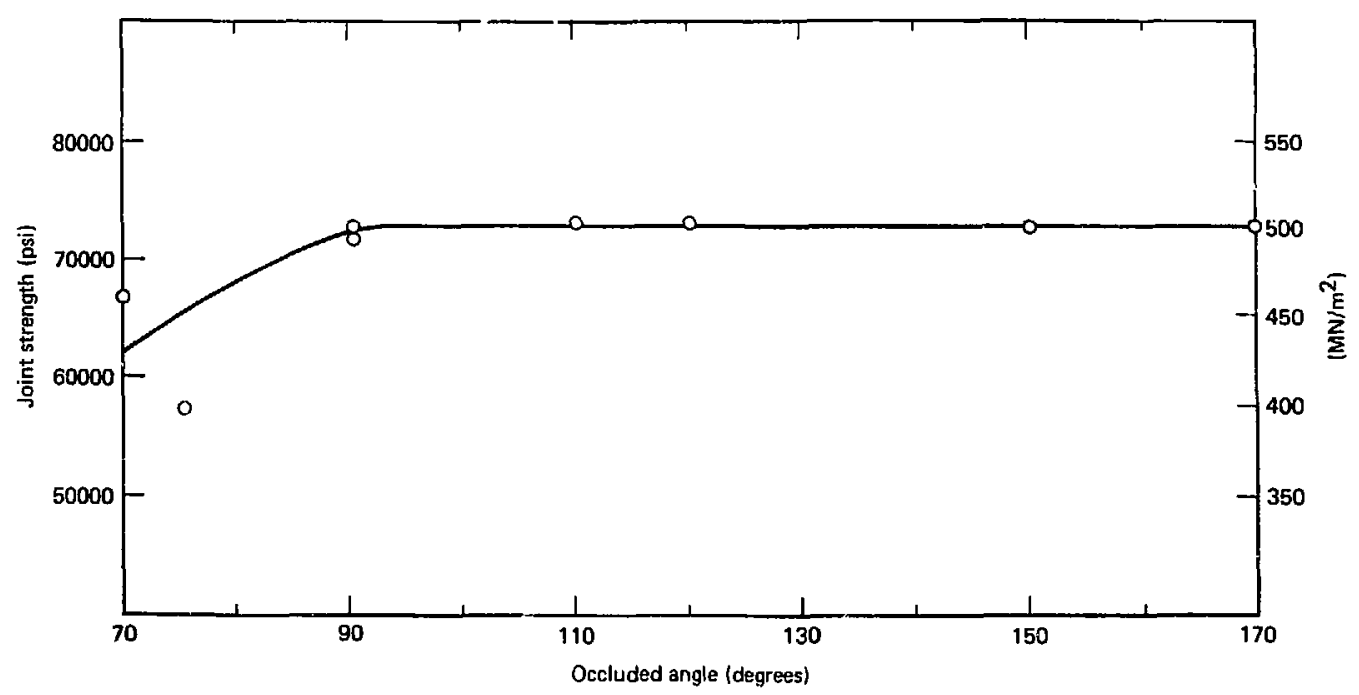

Figure 10. Joint-Strength Data (Circles) as a Function of Occluded Angle for AM363-Ni-AM363.

The curve is a guide for the eye only. 


\section{Comparison of Theory and Experiment}

Figure: : shows the meagured Al-Ni-Al (7075-T6) joint data, represented by circles, and the failure function with $N=1,1.2,2$, and $\infty$. The best fit is found for $\mathrm{N}=1.2$ (solid line). Corresponding data for AM363-Ni-AM263 are shown in Figure 12 along with the predicted curve for $\mathrm{N}=1.2$ (solid line) and, for comparison, curves for $\mathrm{N}=1.0$ and 2.0. The $\mathrm{N}=1.2$ fit is fairly good, although the $\mathbf{N}=1.0$ one is not unreasonable.

Using $\mathrm{N}=1.2$ for $\mathrm{Al}-\mathrm{Ni}-\mathrm{Al}(7075-\mathrm{T} 6)$ joint, the predicted optimum angle (the minimum angle for maximum joint strength, at $\sigma=S_{p}$ ) is 123 degrees, and the measured angle is about 120 degrees. The predicted optimum angle for AM363-Ni-AM333 joint is 83 degrees, and the measured angle is about 90 degrees. The weakes predicted joints for both aluminum alioy and stainless steel occur at $\alpha \simeq 70$ degrees. The reduction in strength for $\mathrm{Al}-\mathrm{Ni}-\mathrm{Al}(7075-\mathrm{T} 6)$ joint is about $159 \mathrm{MN} / \mathrm{m}^{2}$ (from $524 \mathrm{MN} / \mathrm{m}^{2}$ to $364 \mathrm{MN} / \mathrm{m}^{2}$ ) and is about 48 $\mathrm{MN} / \mathrm{m}^{2}$ for AM363-Ni-AM363 joint (from $503 \mathrm{MN} / \mathrm{m}^{2}$ to $455 \mathrm{MN} / \mathrm{m}^{2}$ ). The large reduction in strength for the aluminum alloy joint is caused by its low ratio of interface shear strength to tensile strength $\left(250 \mathrm{sN} / \mathrm{m}^{2}\right.$ to $\left.572 \mathrm{MN} / \mathrm{m}^{2}\right)$.

Usint the shear and tensile strength data listed in Table $I$, the pre icted joint strengths for Al-Ni-Al (2024-T6), Be-Ni-Be, and UTi-Ni-UTi joints are plotted in Figures 13 through 15 . The predicted optimum angles are listed in 


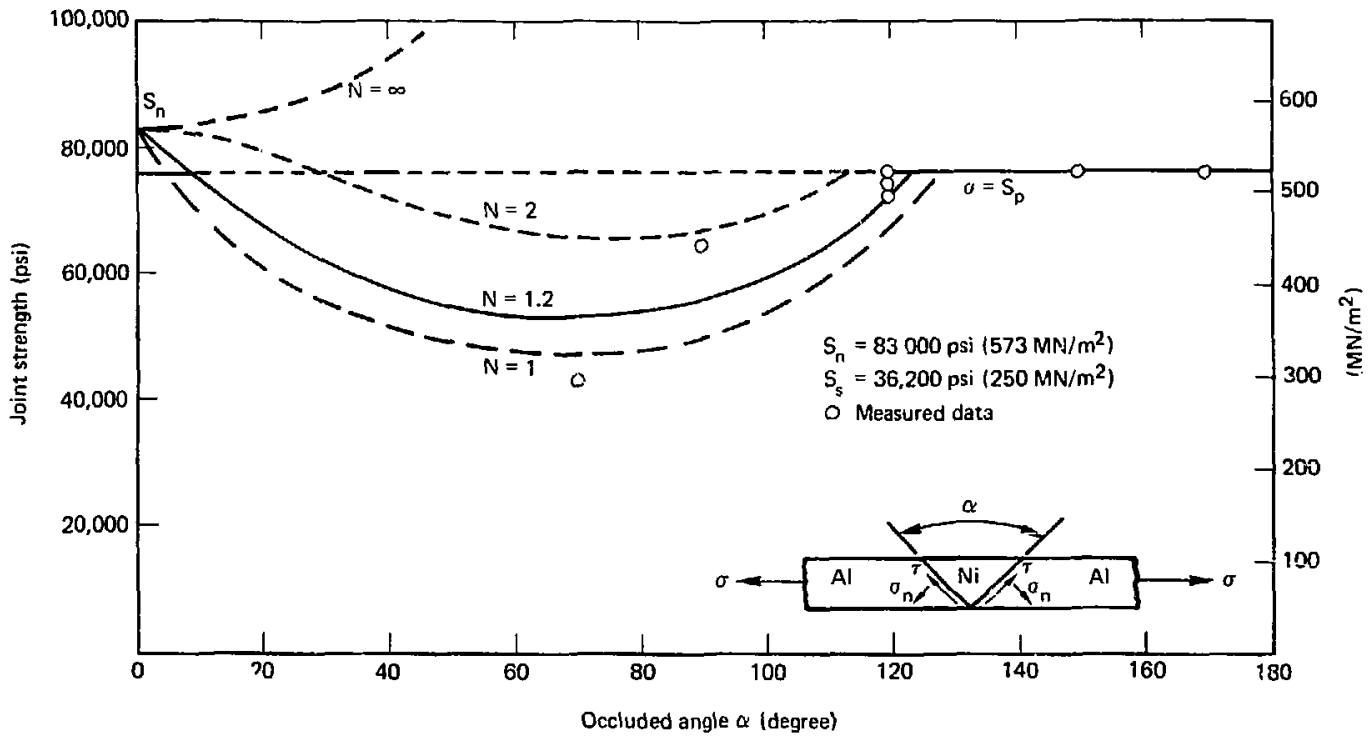

Figure 11. Fit of the Joint-Strength Function as a Function of Occluded Angle to the Al-Ni-Al (7075-T6) Data.

The $N=1.2$ fit (solid line) is the best. Other fits $(N \cdot 1.0,2.0, \infty)$ are shown as dashed curves. 


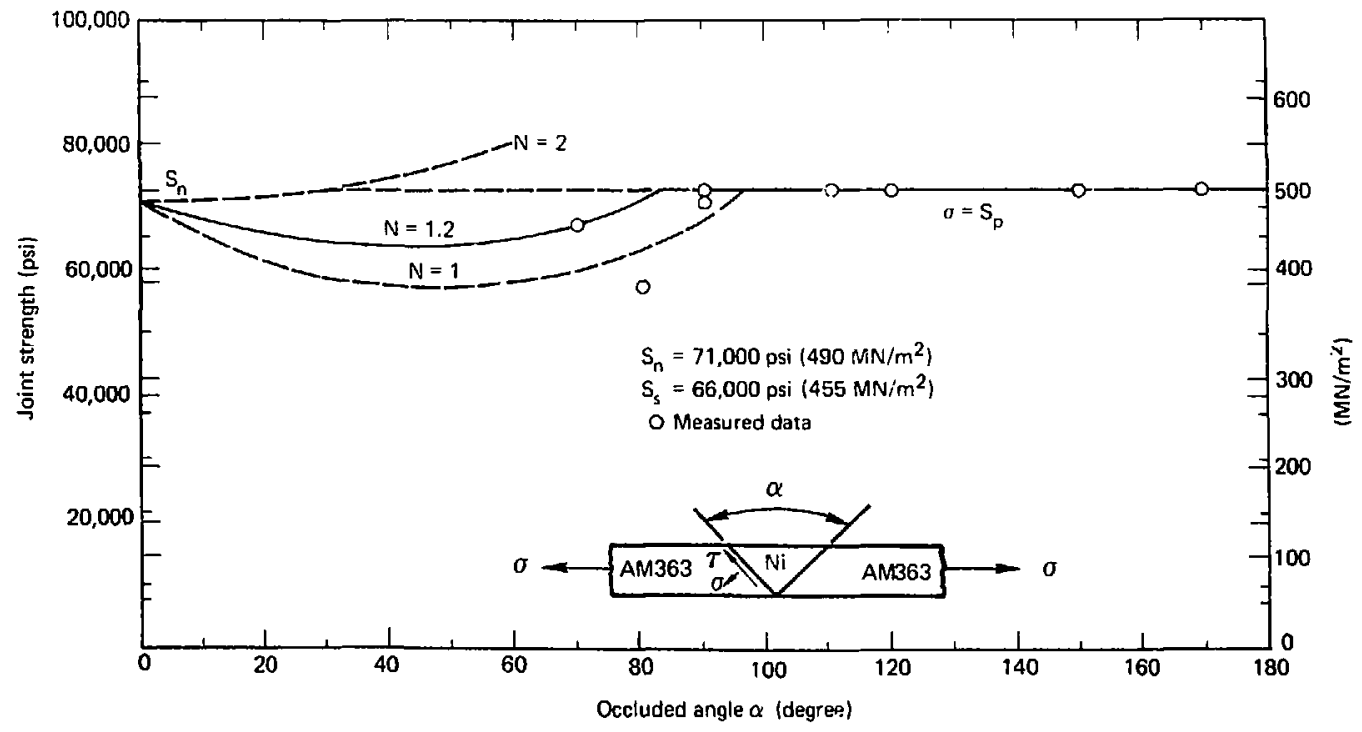

Figure 12. Comparison of the Joint-Strength Function for $N=1.2$ (Solid Line) With Data for AM363-Ni-AM363.

Also shown are theoretical curves (dashed) for $N=1.0$ and 2.0 . 


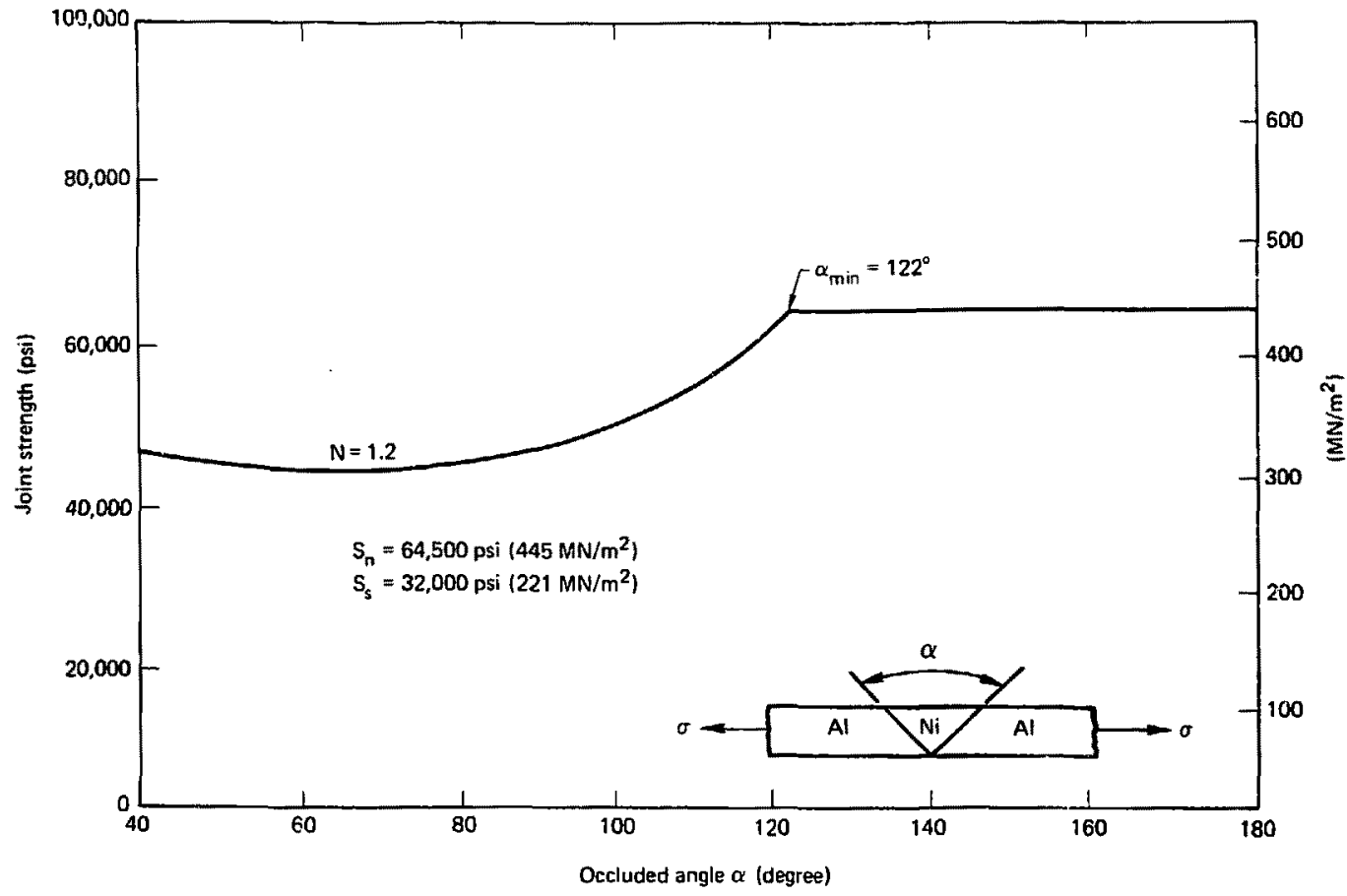

Figure 13. Predicted Joint Sirength as a Function of Occluded Angle for Al-Ni-Al (2024-Th) 


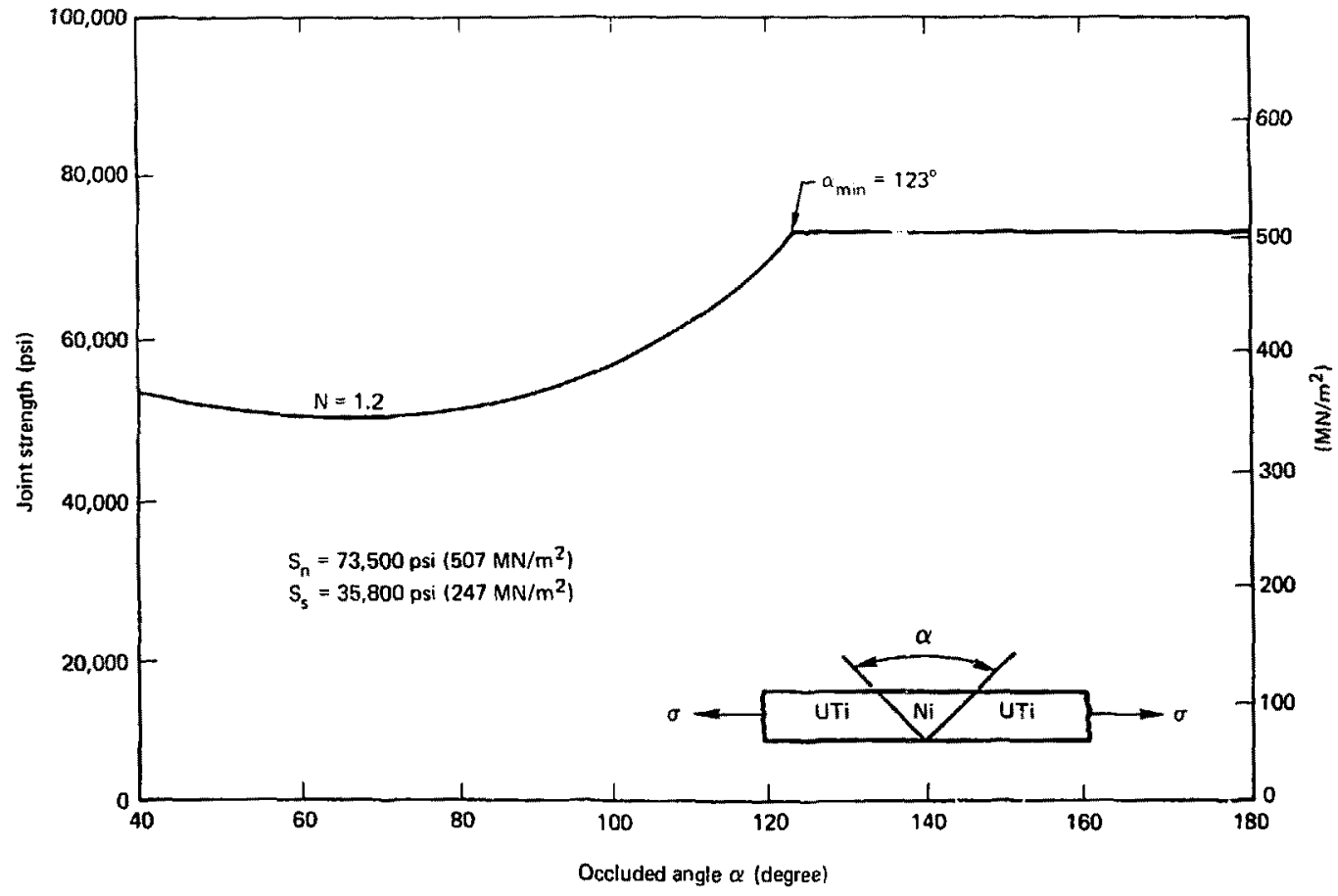




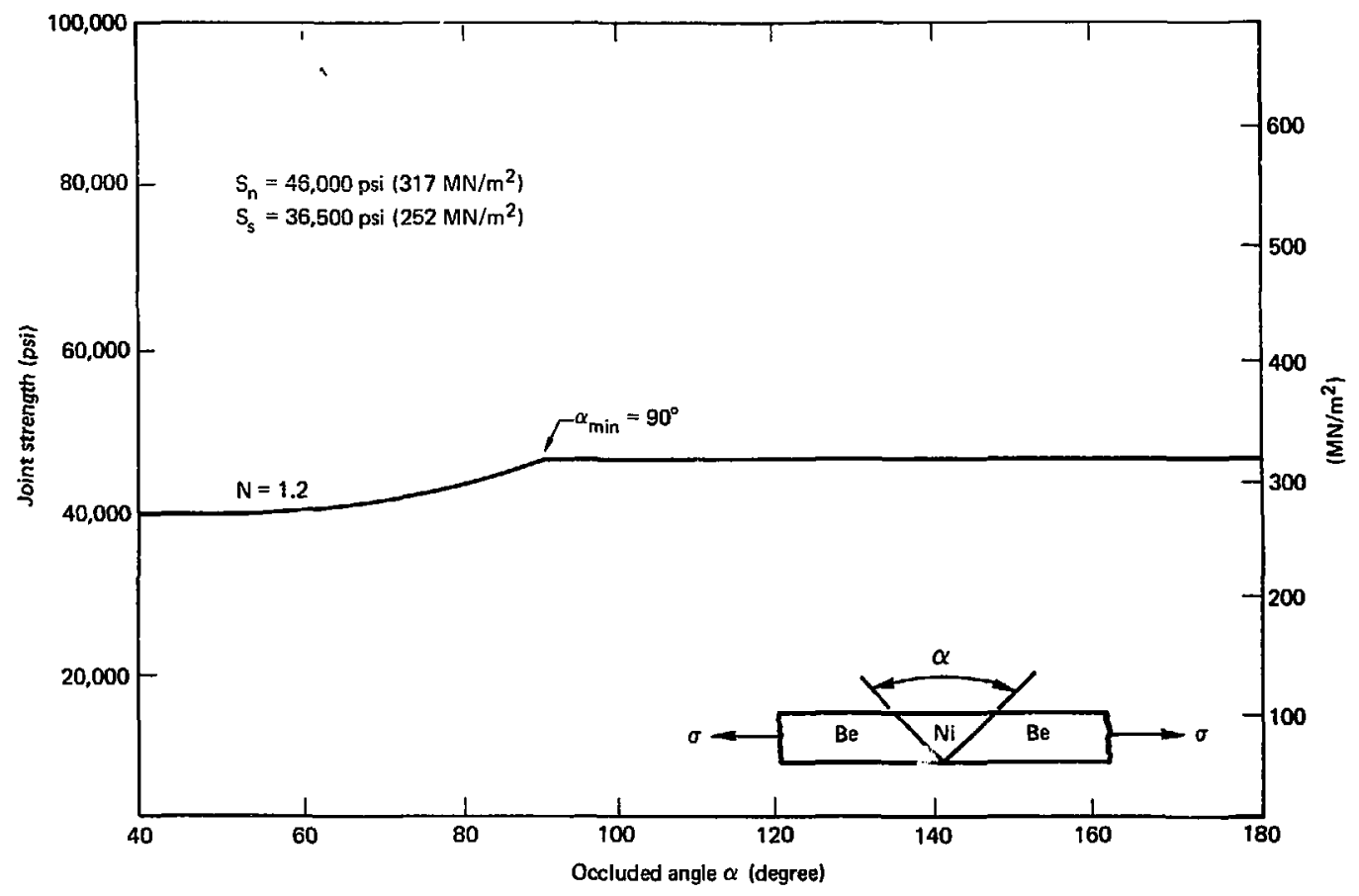

Figure 15. Predicted Joint Strength as a Function of Occluderi Angle for BeNi-Be 
Table II together with optimum angles for 7075-T6 aluminum alloy and AM363 stainless-steel joints. The very small predicied optimum angle ( $\alpha=90$ degrees) for $\mathrm{Be}-\mathrm{Ni}-\mathrm{Be}$ is due to its high ratio of shear strength to tensile strength $(=0.79)$.

TABLE II

PREDICTED AND MEASURED OPTIMUM OCCLUDED ANGLES

\begin{tabular}{lcc}
\hline \multicolumn{1}{c}{ Material } & $\begin{array}{c}\text { Predicted } \\
\text { Optimum Angle }\end{array}$ & $\begin{array}{c}\text { Measured } \\
\text { Optimum Angle }\end{array}$ \\
\hline Al (7076-T6) & $123^{\circ}$ & $120^{\circ}$ \\
Stainless Steel (A M363) & $83^{\circ}$ & $90^{\circ}$ \\
Al (2024-T6) & $122^{\circ}$ & - \\
UTi & $123^{\circ}$ & - \\
Be & $90^{\circ}$ & - \\
\hline
\end{tabular}

VI. Conclusions

A failure criterion has been proposed for predicting the strength as a function of occluded angle of plated joints subjected to an axial load. It is in the form of a power law whose coefficients are extracted from shear and tension test data and whose exponent $\mathbf{N}$ must, for the present, be determined from a fit to a representative set of plated-joint data. For the case of nickel. data on Al-Ni-Al (7075-T6) showed N to be about 1.2, which was found to be consistent with AMB63-Ni-AM363 data. The value of $\mathrm{N}$ of 1.2 appears to 
represent a strong interaction between the shear and tensile stresses at the nickel-parent material interface.

We conclude that the proposed fallure function can be used with confidence as a guide in fabricating nickel-plated joints with otker materials. Predictions are given for the joint atrengths as a function of occluded angle for $\mathrm{Al}-\mathrm{Ni}-\mathrm{Al}$ (2024-T6). UTi-Ni-UTi, and Be-Ni-Be. It would be of interest to test the failure function for other plating materials as well, to see if the general form is universal and, if so, to investigate the variation of $\mathrm{N}$ with plating material. 


\section{RE FERENCES}

1. J. W. Dini and H. R. Johnson, Metals Engineering Quarterly 14, No. 1, 6 (February 1974).

2. J. W. Dini and H. R. Johnson, "Electrochemical Joining: Process, Applications, and Property Data, "SMF Technical Paper AD75-855. Society of Manufacturing Engineers, Dearborn, Michigan, 1975.

3. J. W. Dini and H. R. Johnson, "Adhesion Testing of Deposit-Substrate Combinations, "ASTM STP 640, 305 (1978).

4. R. Hill, "The Mathematical Theory of Plasticity," (Oxford Pres, 1967). pp. 15-23.

5. D. Wood, Metal Industry 36,330 (1938). 
UNLIMITED RE]_EASE

INITIAL DISTRIBUTION:

Bendix Corporation (6)

P. O. Box 1159

Kansas City, MD 64141

Attn: D. L. Stoltz

Union Carbide Corporation (3)

$Y-12$ Plant

P. O. Bisx $Y$

Oak Ridge, TN 37830

Attn: M. Bezik.

F. B. Waldrop

R, Waldrop

Rockwell Interuational (2)

Rocky Flats Plant

P. O. Box 464

Golden, CO 8C401

Attn: G. Mah

R. Riegal

J. Krankota

W. K. Kelley, LLL, L-332

H. J, Wiesner, LLL, I-420

S. D. Hoimes, 1473-3

R. S. Claassen, 5800

M. J. Davis, 5830

U. N. Mattox, 5834

:Г. B. Cook, Jr., 8000; Attn: A. N. Blackwell, 8200

J. F. Barharn, 8110

L. Gutierrez, 8400

J. M. Stephenson, 8116

W. E. Alzheimer, 8120

C. S. Hoyle, 8122

Y. R. Kan, 8122 (10)

B. F. Murphey, B300; Attn: T. S. Gold, 8320

J. L. Wirth, 8340

D. L. Hartley, $\mathbf{8 3 5 0}$

D. M. Schuster, 8310

D. R. Adolphson, 8312

J. W. Dini, 8312 (10)

H. R. Johnson, 8312

R. W. Mar, 8313

i.: R. Hoover, B314

L. A. West, 8315

J. C. Swearengen, 8316 
D. E. Gregson, 8440

R. C. Wayne, 8450

C. M. Tapp, 8460

Publications and Public Information Division, 8265, for TIC (2)

F. J. Cupps, 8265/Technical Library Processes Division, 3141

Technical Library Prosesees Division, 3141 (2)

Library and Security Classification Diviaion, 8266-2 (3) 